\title{
电荷驱动水中氧化物纳米颗粒自组装的原位透射电子显微镜研究
}

吴凯

北京大学化学与分子工程学院, 北京 100871

\section{In Situ Observation of the Self-Assembling of Oxides Nanoparticles in Water by Electron Microscopy}

WU Kai

College of Chemistry and Molecular Engineering, Peking University, Beijing 100871, P. R. China.

Email: kaiwu@pku.edu.cn

由于氧化物纳米材料具有较大的比表面积 和表面活性, 因此被广泛地应用于催化、能源储 存、纳米器件等各种领域。人们通过各种不同的 合成技术手段, 实现对氧化物纳米材料表面形貌 进行调控, 进而获得具有优异性能的纳米材料。 在各种纳米材料合成手段中, 可控性自组装技术 是一种有效调控纳米材料尺寸及形貌特征的方 法, 在纳米材料的合成以及制备方面具有较大的 应用潜力 1 。纳米颗粒的自组装过程及其自组装的 结构形态特征, 常常受到纳米颗粒之间的范德华 力、氢键、静电力、疏水性、偶极矩等相互作用 的影响 ${ }^{2-5}$ 。

原位研究纳米颗粒的自组装过程, 有助于人 们更好地了解纳米材料自组装的驱动力及其原 理, 从而为改进实验工艺提供理论技术指导。然 而, 由于纳米颗粒的自组装过程往往发生在液体 之中, 用常规的透射电镜无法进行观察研究。因 而, 需要通过在透射电镜内搭建液体腔室的技术, 实现在微观尺度下观察研究液体环境中纳米材料 的结构演变及自组装过程等 ${ }^{6-8}$ 。鉴于此研究领域 的重要性, 北京工业大学固体微结构与性能研究 所隋曼龄研究组的赵喆、卢岳、张振华等人利用液 体环境透射电子显微镜, 原位观察了四氧化三钴 纳米棒在水中的自组装过程。

该工作已在物理化学学报上在线发表(doi: 10.3866/PKU.WHXB201806012) ${ }^{8}$ 。该工作通过电 子束辐照改变水溶液的介电常数, 从而导致水的 导电性增强, 进而利用液体环境透射电子显微镜
观察四氧化三钴纳米棒之间产生相对运动, 以及 自组装成纳米棒的生长动力学进程。同时, 他们发 现四氧化三钴纳米棒的晶面存在互补式自组装现 象: 随着纳米棒之间的距离逐渐接近, 纳米棒之间 的相对运动速率逐渐增加, 纳米棒之间的相互作 用力也逐渐增强。通过对四氧化三钴纳米棒进行 形貌特征表征以及所暴露的晶面分析, 他们认为 四氧化三钴纳米棒表面的极性晶面电荷补偿不完 全 $^{9}$, 表面剩余电荷的极性对纳米棒之间的自组装 起到了决定性的影响。希望本文能够为了解氧化 物纳米材料的自组装现象提供认识和帮助。

\section{References}

(1) Chen, Q.; Cho, H.; Manthiram, K.; Yoshida, M.; Ye, X.; Alivisatos, A. P. ACS Cent. Sci. 2015, 1, 33. doi: 10.1021/acscentsci.5b00001

(2) He, T.; Chen, D.; Jiao, X.; Wang, Y. Adv. Mater. 2006, 18, 1078. doi: 10.1002/adma.200501864

(3) Zhang, Y. C.; Pan, L.; Liu, J.; Song, J.; Li, Z.; Zhang, X.; Wang, L.; Zhou, J. Appl. Surf. Sci. 2017, 401, 241. doi: 10.1016/j.apsusc.2017.01.031

(4) Takada, S.; Fujii, M.; Kohiki, S. Nano Lett. 2001, 7, 379. doi: $10.1021 / \mathrm{n} 1015538 \mathrm{x}$

(5) Elbert, K. C.; Jishkariani, D.; Wu, Y.; Lee, J.; Donnio, B.; Murray, C. B. Chem. Mater. 2017, 29, 8737. doi: 10.1021/acs.chemmater.7b02928

(6) Lu, Y.; Yin, W. J.; Peng, K. L.; Wang, K.; Hu, Q.; Selloni, A.; Chen, F. R.; Liu, L. M.; Sui, M. L. Nat. Commun. 2018, 9, 2752. doi: 10.1038/s41467-018-05144-1 
(7) Lu, Y.; Geng, J. G.; Wang, K.; Zhang, W.; Ding, W. Q.; Zhang, Z. H.; Xie, S. H.; Dai, H. X.; Cheng, F. R.; Sui, M. L. ACS Nano 2017, 11, 8018. doi: 10.1021/acsnano.7b02656

(8) Zhao, Z.; Lu, Y.; Zhang, Z. H.; Sui, M. L. Acta Phys. -Chim. Sin. 2019, 35 (5), 539. [赵喆, 卢岳, 张振华, 隋曼龄. 物理化学学报,
2019, 35 (5), 539.] doi: 10.3866/PKU.WHXB201806012

(9) Yu, R.; Hu, L. H.; Cheng, Z. Y.; Li, Y. D.; Ye, H. Q.; Zhu, J. Phys. Rev. Lett. 2010, 105, 226101. doi: 10.1103/PhysRevLett.105.226101 